\title{
"Not just a HR trend". Behind the curtains of diversity : a statistical analysis of role distribution and hiring practices at a technology company.
}

\author{
Camille Akmut
}

\begin{abstract}
A look at professional roles distributions, and hiring practices at a representative start-up / technology company. Based on the statistical analysis of a database with 1700 individual information.
\end{abstract}




\section{Introduction}

\subsection{Origin and context of the dataset}

In 2017, SoundCloud laid off almost half of its employees. These workers organized and put together a (virtual) (or electronic) bulletin board where those affected published their information for potential prospective employers ${ }^{1}$. A news publication at the time reported that " 40 percent of its staff $\left(\begin{array}{lll}\ldots & 173\end{array}\right.$ people)" ${ }^{2}$ had been fired.

\subsection{Significance and method}

These data offer a - to our knowledge - never-before made available insight into the world of technology companies, and specifically start-ups (ex, and current), from the point of view of their hiring practices. And, beyond, they offer, when analyzed, a general structure of the (corporate) technology world.

Going forward, we follow the classic steps of quantitative work that consists in : I. (description of the) data, II. (laying bare of the choices involved in) categorization, and III. statistics and IV. analysis, where critic and generalization play a big role.

\section{Data}

9 general categories (materialized as columns). One category has 5 sub-divisions. This makes 13, in total. Containing 130 entries (for as many individuals, materialized as rows). Or, close to 1700 individual information.

\section{Categorization}

The hardest work by far in this undertaking was creating coherent and consistent categories - we open up here our choices to scrutiny.

This is not uncommon for such type of work, but, in this case, the case of technology companies, the task was particularly difficult, for reasons we explain and that should be immanent below.

We signify native designations, in a manner akin to that of anthropologists, with the combined use of quotes and italics, to distinguish them from our own categories (where me may use quotes, to identify them as such, which is to say as constructs, but never together or in combination with italics).

It should be kept in mind that the following are self-descriptions, not (official) categories selected from (pre-defined) forms, which makes them all the richer.

\footnotetext{
${ }^{1}$ Had they had a union, or some similar workers' organization, they would have been able to organize in other, much more effective ways. (Rather than to go from one, questionable, company to the next.)

${ }^{2}$ Lockett 2017.
} 


\subsection{Gender}

Gender was not provided, and so we used first names as principal proxy. ${ }^{3}$ This is an imperfect proxy (e.g. Alexis or Hadley). We used social media accounts to make sure the final categorization was correct. This enabled a coverage of $100 \%$ of the population ${ }^{4}$.

\section{$3.2 \quad$ Roles}

We have subsumed the various roles declared - many of them eclectic, sometimes having to deal with what can only be described as creative titles - under traditional nomenclatures.

In presenting these various roles, here, we move along an approximate axis of most technical to least technical (from "engineering" to "human resources" through "project/product management").

\subsection{1 (Software) Engineering}

E.g. "Backend Engineer", "Software Engineer", "iOS Engineer", "Android Engineer". This category presented relatively the least difficulties.

\subsubsection{Data science}

We distinguished data science positions from (software) engineering. E.g. "Data Engineer", "Data Scientist", "Data Analyst" .

But, these could be both further subsumed under "technical positions" (although some, and some important, information would be lost, as these professions tend to be more populated by women, we believe, and expect, than strictly engineering positions (in particular data analysts as opposed to data scientists)).

\subsubsection{IT (Hardware)}

E.g. "IT Support ...", "IT Technician". With the same remark as above, but with even more caution considering the divides between software and hardware already laid out elsewhere i.e. many software engineers conceive of themselves, and their profession has been constructed, in opposition to those, considered less(er), of "IT" (Information Technology).

\footnotetext{
${ }^{3}$ This was sometimes made hard by the fact that some of the respondents confused the two categories of first and last names.

${ }^{4}$ Many of them cultivated extensive online presences (LinkedIn (over 95\% of the studied population), Twitter, Kaggle, etc.).

${ }^{5}$ All of these categories cover varied realities, and backgrounds (in particular data analysts have often backgrounds that are most distant from classical software engineering), are subject to much debate, and many liberties can be taken in their attribution - as will become even clearer with the rest of this population's choices or indications - but data science is the closest to software engineering in our view, and they may eventually be subsumed together under "technical positions" (their practices are similar).
} 


\subsubsection{UX/UI}

Other categories were not lacking in what appeared sometimes to be fantasy titles or (bordering on) grandiloquent embellishments or exaggerations : "Brand Designer" ("Content Art Director"), "Senior Product Designer", "Head of Design", "Product designer", "Audience/Market Research Manager", "Audience Research Lead", and finally "Creative Services Manager"6 etc. etc.. These we placed under the general category of "UX/UI" (User Experience/Interface) ${ }^{7}$.

\subsubsection{Product, Project, Content Management}

Finaly, we placed the - even more colorful, inventive - titles of "UX Writer / Content Strategist", "Senior Content Manager, Digital Music Specialist", "Content Operations Intern" or "Technical Product Manager, Data Platform", or "Project Manager Audience Research" (elsewhere "Product Manager, Creator Experience"), "VP Creator Product" (elsewhere "Senior Director of Product"), "Content Experience Manager / Community Manager", "Senior Technical Account Manager" , and finally "Intern, Learning \& Development"9 and "Business Administration Specialist"10, or otherwise "Editor" under a general category of "Product, Project, Content Management".

\subsubsection{Client relations}

We finally created a category of "Client relations" to subsume the majority of the rest of the population: "Label Relations", "Director Business Development $\&$ Content Partnerships", "Head of International Sales / Brand Partnerships", and "Copyright Operations Specialist" or "Director of Eng Creators 83 Rightsholders", "Senior Manager New Markets", "Global communications manager", "Sr. Manager, Strategy $\&$ Business Development", "Director of Community Operations", "Content Relations Manager"11...

We also placed "Community Support Specialist", "Senior Community Support Manager" or "Partner Support Lead ..." under "Client Relations", having first created a separate category of "Support". We also placed varied marketing roles (previous "Marketing") into this category.

\footnotetext{
${ }^{6}$ Only attributable under a correct category through cross-reference. Through nominal title alone we were inclined, and had first put it under "Client relations".

${ }^{7}$ Coherent with their current positions, also cross-referenced.

${ }^{8}$ Also only attributable to a correct category through cross-reference with the internal category of "Expertise (5 keywords)", where this member of the population had given "Project ... management" as first expertise.

${ }^{9}$ Cross-reference.

${ }^{10}$ Cross-referenced this time internally through the additional (native) category "Expertise (5 keywords)".

${ }^{11}$ First placed under "Product, Project, Content Management", but a cross-reference with "Expertise (5 keywords)" enabled a more accurate placement (although these two categories have much overlap in places).
} 


\subsubsection{Human Resources}

For instance "Workplace Specialist", "People Team Operations", "Technical Recruiting Partner", "Employer Branding Partner", "Internal Communications Manager", "Director, Recruitment $\&$ Employer Branding", "Operations Manager" (not to be confused with IT operations ${ }^{12}$ ) - are subsumed under the general category of human resources. Where doubts subsisted, we also relied on social media accounts to determine the current position.

\subsubsection{Accounting}

-. (Few members.)

\subsubsection{Legal}

E.g. "Policy Manager".

\subsubsection{Further notes}

If we had to give a special qualifier, we do this in parenthesis : "Engineering (Management)" or "Product, Project, Content Management (Intern)" where we saw relevant to add this information. Engineering management positions for instance can subsume or cover a variety of realities, from past engineers turned managers to non-engineers (PM's ${ }^{13}$ ) turned engineering managers ${ }^{14}$.

These various liberties taken with titles can be explained by the fact that many of the members of this population - particularly involved in the more creative-leaning professions offered by or of the technology world, or otherwise product or project management - are still attached to identities such as that of artists, or musicians, or writers, or otherwise "DJ's" or professional "guitarists", which they were, or continue to try to be, while also maintaining lucrative corporate careers, or simply trying to pay their bills like (most of) everyone else.

\section{Statistics}

\subsection{Distribution of roles according to categories}

\begin{tabular}{|l|l|l|} 
Category & $\mathbf{n}$ & $\mathbf{\%}$ of total \\
\hline Engineering & 33 & $25 \%$ \\
\hline Data science & 19 & $14 \%$ \\
\hline
\end{tabular}

\footnotetext{
${ }^{12}$ This also we were able to determine through cross-references with social media profiles. ${ }^{13} \mathrm{PM}$ is the native designation used by this population to mean project managers (and sometimes perhaps product managers, all of these identities, and their real uses, being somewhat nebulous).

${ }^{14}$ One member of this population self-described as "Agile Facilitator/ Engineering Manager" for instance.
} 


\begin{tabular}{|l|l|l|}
\hline IT & 2 & $1 \%$ \\
\hline UX/UI & 12 & $9 \%$ \\
\hline Project management ... & 20 & $15 \%$ \\
\hline Client relations & 29 & $22 \%$ \\
\hline Human Resources & 12 & $9 \%$ \\
\hline Legal & 2 & $1 \%$ \\
\hline Accounting & 1 & $0.07 \%$ \\
\hline
\end{tabular}

Table 1: Distribution of SoundCloud employees according to roles (categories). $\mathrm{n}=130(100 \%)$

\subsection{Distribution of roles based on even broader categories}

\begin{tabular}{|l|l|} 
Category & $\mathbf{n}(\mathbf{\%})$ \\
\hline Technical roles & $\mathbf{5 4}(\mathbf{4 1 \%})$ \\
\hline - Engineering & 33 \\
\hline - Data science & 19 \\
\hline - IT & 2 \\
\hline Design & $\mathbf{1 2}(\mathbf{9 \%})$ \\
\hline - UX/UI & 12 \\
\hline Project management and Client relations & $\mathbf{4 9 ( 3 7 \% )}$ \\
\hline - Project management ... & 20 \\
\hline - Client relations & 29 \\
\hline Human Resources, Legal, Accounting, etc. & $\mathbf{1 5}(\mathbf{1 1 \%})$ \\
\hline - Human Resources & 12 \\
\hline - Legal & 2 \\
\hline - Accounting & 1 \\
\hline
\end{tabular}

Table 2: Distribution of SoundCloud employees based on even broader categories. $\mathrm{n}=130(100 \%)$

At first sight, there is nothing unusual about the representation of our population, and it may be considered to be representative : with the bulk of personnel employed in 1 . technical roles 2 . project/product/content management followed by human resources.

This is representative of many job distributions at similar companies, and to convince oneself of that, one may look at any of them, but we provide here one example for the convenience of the reader. 


\section{Business Development}

20 positions
Business Support

41 positions

\section{Content}

36 positions
Data \&Analytics

71 positions
Design \&UX

20 positions
Engineering \& IT

110 positions

\section{Product} Management

42 positions
Sales \& Marketing

46 positions

Figure 1: Jobs advertised at Spotify at the time of writing.

Job advertisements of course are only a proxy, one may argue they only represent the current needs, which may be fluctuating, but this we present as first reference ${ }^{15}$.

With "Engineering and IT" constituting the biggest category.

\subsection{Gender-differentiated roles distributions}

We come to the most interesting part of this analysis.

Which roles in the technology sector have the most men? Which ones the most women? And, how is a - self-conceived if not in actuality - progressive company - here SoundCloud - able to achieve their purported goals of diversity? We look at these, and other questions, here.

We do not limit ourselves to the wishes of these companies - so when they publish reports, most of them self-published, or whose integrity when published by third parties can be doubted, or when they include diversity pages on their websites - and neither their promises "to do better", of which we have heard many pious ones during recent court and committee hearings, in recent times, but their actual practices. This is one of the great advantages of statistics (it is hard to be angry at numbers, though they can be manipulated).

\footnotetext{
${ }^{15}$ A much better reference is constituted by "Team", "Staff" - they have many names pages at these various companies, when they are available.
} 


\subsection{Overall gender distribution}

\begin{tabular}{|l|l|} 
Gender & $\mathbf{n}(\mathbf{\%})$ \\
\hline $\mathrm{m}$ & $77(59 \%)$ \\
\hline $\mathrm{f}$ & $53(40 \%)$ \\
\hline
\end{tabular}

Table 3: Overall gender distribution of SoundCloud employees. $\mathrm{n}=130(100 \%)$

Generally, statistics presented by these companies are what one may call "global", or total, statistics - like we do here. Men make up $60 \%$ of SoundCloud employees as can be determined by our population, while women make up $40 \%$ of the rest.

Their reports will then conclude that - based on the unsaid fact of an about equal distribution of men and women in demographics - efforts remain to be done.

They rarely show specific statistics that differentiate between genders among specific roles, or do so in awkward, for the reader, but pleasant, for the company, manner.

We turn to these questions now. How many female engineers? How many male engineers? How many women employed in administration? Etc.

\subsection{Gender distributions by role : technical vs. non- technical (the great divide)}

\begin{tabular}{|l|l|l|l|} 
Category & Men & Women & n (\%) \\
\hline Engineering & $26(78 \%)$ & $7(21 \%)$ & $33(100 \%)$ \\
\hline Data science & $14(73 \%)$ & $5(26 \%)$ & $19(100 \%)$ \\
\hline IT & $1(50 \%)$ & $1(50 \%)$ & $2(100 \%)$ \\
\hline UX/UI & $6(50 \%)$ & $6(50 \%)$ & $12(100 \%)$ \\
\hline Project management ... & $9(45 \%)$ & $11(55 \%)$ & $20(100 \%)$ \\
\hline Client relations & $15(51 \%)$ & $14(48 \%)$ & $29(100 \%)$ \\
\hline Human Resources & $6(50 \%)$ & $6(50 \%)$ & $12(100 \%)$ \\
\hline Legal & $0(0 \%)$ & $2(100 \%)$ & $2(100 \%)$ \\
\hline Accounting & $0(0 \%)$ & $1(100 \%)$ & $1(100 \%)$ \\
\hline
\end{tabular}

Table 4: Gender distribution of SoundCloud employees according to specific roles. $\mathrm{n}=130(100 \%)$

At SoundCloud, women make up only $20 \%$ of software engineers, while men largely dominate this area (80\%). This is compared with $40 \%$ versus $60 \%$ for the overall population.

Among the 7 women in engineering, 1 is an intern (there were no male 
interns, in this area, or any other in fact ${ }^{16}$ ) and 1 is an engineering manager with "project management" listed among their expertise skills.

Data science represents an area that is slightly more populated by women, as per our assumptions and our general knowledge of the field. This may be interpreted as this area being slightly less in demand or competitive or prestigious, which does correspond to some native classifications at least ${ }^{17}$.

In IT, also congruent with out beginning assumptions, and otherwise ethnographic observations, women are found even more often than in the two previous - technical - areas of software engineering and data science. The sub-sample population however is very small.

Also congruent with our observations and impressions, the area of UX/UI is a largely "feminine" one, with - and in the particular sense - of their being about the same number of women and men, if not more women than men, involved in this area.

The rest remains also, so : an equal distribution, if not preponderance of women in project management and client relations and human resources.

If we were to overestimate the meanings of these numbers, and to express their un-saids, we might be lead to believe that, at this company, though not unlike any other of its sector, "women are good as secretaries, but not programmers".

But, no such thing can be said here.

\begin{tabular}{|l|l|l|l|} 
Category & Men & Women & $\mathbf{n ~ ( \% )}$ \\
\hline Engineering & $26(78 \%)$ & $7(21 \%)$ & $33(100 \%)$ \\
\hline Non-Engineering & $51(52 \%)$ & $46(47 \%)$ & $97(100 \%)$ \\
\hline
\end{tabular}

Table 5: Gender distribution of SoundCloud employees according to engineering vs. non-engineering. $\mathrm{n}=130(100 \%)$

\begin{tabular}{|l|l|l|l|} 
Category & Men & Women & $\mathbf{n}(\%)$ \\
\hline Technical & $41(75 \%)$ & $13(24 \%)$ & $54(100 \%)$ \\
\hline - Engineering & & & \\
\hline - Data science & & & \\
\hline - IT & & & \\
\hline Non-technical & $36(47 \%)$ & $40(52 \%)$ & $76(100 \%)$ \\
\hline - UX/UI & & & \\
\hline - Project management ... & & & \\
\hline - Client relations & & & \\
\hline - Human Resources & & & \\
\hline - Legal & & & \\
\hline - Accounting & & & \\
\hline
\end{tabular}

\footnotetext{
${ }^{16}$ We come back to this fact later.

${ }^{17}$ E.g. various results to a (non-restrictive) search query such as "data science is not software engineering".
} 
Table 6: Gender distribution of SoundCloud employees according to technical vs. non-technical roles. $\mathrm{n}=130(100 \%)$

\subsection{Gender distributions of interns at SoundCloud : in- terns are women}

We can go further with these analyses, and we do so here thanks to the availability of information such as "manager" or "intern" roles.

\begin{tabular}{|l|l|} 
Gender & Role \\
\hline f & Client relations (Intern) \\
\hline f & Engineering (Intern) \\
\hline f & Product, Project, Content Management (Intern) \\
\hline f & Product, Project, Content Management (Intern) \\
\hline
\end{tabular}

Table 7: Gender distribution of SoundCloud interns. $\mathrm{n}=130(100 \%)$

At SoundCloud, it may almost be said that "interns are women, and women are interns" (in mind, if not reflected in practices, at least). 


\section{Conclusion}

Technology companies, with the (often false) revolutionary airs that their executives give themselves and give us, with their many perks, that some consider awesome, and other tragi-comical, have accustomed us to many things. They have promised even more.

Certain companies have a reputation - self-given, self-conceived, sometimes earned - for progressive politics. No matter what, we choose to prefer here numbers over all things.

Tomorrow, they may promise to solve world poverty thanks to AI, or to find a solution for tech-displayed San-Franciscans by providing them with the necessary technological education... (So they may in turn displace their fellow neighbors to even further fringes of the city, and on.) But, today, we simply look at their practices.

In this study, based on a complete population of 130 SoundCloud employees, having been laid off and posted their information online, we looked at their various characteristics and established objectively what diversity meant : diversity, in these companies, is found at most at a global level.

This is to say that when taking the total of employees and measuring genderbased statistics, one may find that about half - or close enough - are equally distributed between men and women employees. But, when looking at engi-

neering vs. non-engineering categories, one finds a very different reality : at SoundCloud, a progressive technology company if there is any, only 1 in 5 engineers is a women.

This is coherent with the rest of the technology sector.

Diversity, to them, should never come at the cost of business.

$*$

Epilogue : in which we learn nothing about nothing.

Many of the members of this population then went on to work for other start-ups of the Berlin area, or closely related companies : Spotify, Deezer, Zalando, N26, Reddit, Facebook... Others returned to SoundCloud.

For, "What is the robbing of a bank compared to the founding of a bank?" 


\section{Bibliography}

Lockett, Dee. 2017. "SoundCloud Plans to Forge Ahead Independently, Laying

Off Almost Half Its Staff." Vulture, 06/06. http://www.vulture.com/2017/

07/soundcloud-makes-major-layoffs-to-remain-independent.html

Spotify Jobs. https://www.spotifyjobs.com/. 
Diversity \& Inclusion at SoundCloud

SoundCloud is a truly global company that has over 30 different nationalities, working together to bring the world the most open and authentic, peoplepowered music streaming service.

We believe that focussing on diversity and inclusion is a business imperative, not just a HR trend, and by having a diverse workforce our company and platform is enriched. Diverse teams who are innovative and creative tend to blend various ideas, styles and backgrounds, as different ways of working are proven to create better results. By breaking with homogeneity, we become more aware of our own potential biases and awareness is the starting point for personal growth.

https://medium.com/@SoundCloud/diversity-inclusion-at-soundcloud-ce6b9403f48b

Jan 11, 2017 


\section{Appendix : a minimal hacker's toolbox (101 intro to statistics)}

Disclaimer : no machine learning needed, most of the statistics pertaining to the social characteristics of the technological world can be obtained with just a few basic / simple equations.

$=\operatorname{COUNTIF}(\mathrm{B} 2: \mathrm{B} 131, " * \mathrm{f} * ”)$

$\Rightarrow \mathrm{SUM}(\mathrm{C} 2: \mathrm{C} 10)$

Standard Filter $\rightarrow$ Condition $=$ Value $\ldots$ 